\title{
Comparing effectiveness, cost- and time-efficiency of control options for Xanthomonas wilt of banana under Rwandan agro-ecological conditions
}

\author{
Guy Blomme $\mathbb{D}$ - Petronille Dusingizimana • Jules Ntamwira • \\ Elizabeth Kearsley $(\mathbb{D})$ Svetlana Gaidashova $(\mathbb{D}$ - Anne Rietveld $(\mathbb{D}$ - \\ Boudy Van Schagen (D) - Walter Ocimati $($ C)
}

Accepted: 10 March 2021 / Published online: 20 March 2021

(C) The Author(s) 2021

\begin{abstract}
Xanthomonas wilt of banana (XW) is a major disease affecting banana throughout East and Central Africa (ECA). Initial control was through complete diseased mat uprooting (CDMU), which had limited adoption due to high labour demands
\end{abstract}

G. Blomme $(\bowtie)$

Bioversity International, Addis Ababa, Ethiopia

e-mail: G.Blomme@ cgiar.org

P. Dusingizimana

Bioversity International, Kigali, Rwanda

J. Ntamwira

Bioversity International, Bukavu, Democratic Republic of Congo

E. Kearsley

BlueGreen Labs, Antwerp, Belgium

S. Gaidashova

Rwanda Agricultural Board, Rubona, Rwanda

A. Rietveld

Bioversity International, Den Haag, The Netherlands

B. Van Schagen

KIT - Royal Tropical Institute, Amsterdam, The Netherlands

W. Ocimati

Bioversity International, Kampala, Uganda and cost. Further research demonstrated single diseased stem removal (SDSR) was an effective, less labour intensive and less costly alternative to CDMU. A comparative assessment of the two control practices was needed to foster uptake by policy makers, especially in countries like Rwanda where SDSR had not been tested or scaled up. To test SDSR in Rwanda, a study was conducted in farmers' fields comparing the effectiveness, labour cost and time demands of CDMU and SDSR. SDSR was equally effective as CDMU for XW control, with initial XW incidences of 3.0 to $9.4 \%$ being reduced to $<0.5 \%$ within 3 months of using either method. The major benefit of SDSR lies in its significantly lower resource requirements. The total time needed for applying SDSR on a single plant was $88 \%$ less, averaging $4.3 \mathrm{~min}$ (standard deviation, $\mathrm{sd}=0.3)$ compared to $36.5 \mathrm{~min}(\mathrm{sd}=4.5)$ for CDMU on a complete mat. Accordingly, the cost of labour was significantly lower for SDSR. The main cost of CDMU (78\% of total cost) arose from the need to replant with healthy banana plantlets. The total cost of SDSR (26 Rwandan Francs [Frw], sd = 2) was $96 \%$ lower than that for CDMU (619 Frw, $\mathrm{sd}=27$ ). Hence, the incentive to use SDSR for managing XW is very high. These findings will boost SDSR adoption by both policy makers and farmers in ECA.

Keywords CDMU $\cdot$ Cost-benefit analysis $\cdot$ Disease incidence $\cdot$ SDSR 


\section{Introduction}

Xanthomonas wilt (XW) of banana (Musa spp.) is a destructive disease caused by the bacterium Xanthomonas vasicola pv. musacearum (Xvm; previously Xanthomonas campestris pv. musacearum). The disease was first observed on enset (Ensete ventricosum) in the 1930's (Castellani 1939) and later by Yirgou and Bradbury (1968). On Musa spp. (banana and plantains, hereafter banana(s)), XW was first reported in Ethiopia in 1976 (Yirgou and Bradbury, 1974). In the East and Central African (ECA) region, it was first reported in Uganda in 2001 (Tushemereirwe et al. 2004), and has since spread to all highland banana growing regions in the ECA (Blomme et al. 2014; Carter et al. 2010; Mbaka et al. 2007; Ndungo et al. 2006; Reeder et al. 2007).

Infection in banana occurs when the Xvm bacterium enters a healthy plant's vascular system through an open wound on the male inflorescence or through wounds caused by tools on any part of the plant or mat (Blomme and Ocimati 2018). The disease is commonly spread by flying insect vectors (mainly bees), which transmit the inoculum from the inflorescence of a diseased plant to a healthy plant while sourcing nectar and pollen (Tinzaara et al. 2006). Contaminated farm tools and infected planting materials are also important modes for spread of XW (Eden-Green 2004). Spread via birds and bats, browsing cattle and small ruminants can also occur, although to a lesser extent (Blomme et al. 2017a; Blomme and Ocimati 2018; Buregyeya et al. 2014).

The disease has severe effects on food security and income of banana dependent households and production systems where banana predominates. Yield losses can be $100 \%$ when control of XW is delayed (Blomme et al. 2014). Muchuruza and Melchior (2013) reported yield and income losses of $84 \%$ and $64 \%$, respectively, in Tanzania, while Nkuba et al. (2015) reported a 35\% decline in sales and doubling of healthy bunch prices in Rwanda and Tanzania. The crop loss can result in land degradation as soil becomes exposed due to uprooting of infected plants and mats. Ecosystem services including erosion control and carbon sequestration can be impaired in severely affected areas (Ocimati et al. 2016, 2019). Thus, timely and effective management strategies are needed to combat XW.

Management of XW has relied entirely on cultural practices as all edible banana in the ECA are susceptible to the disease (Ssekiwoko et al. 2006; Kagezi et al. 2006; Tushmereirwe et al. 2006). During early stages of an XW epidemic several practices were advocated. These include complete uprooting of diseased mats (containing at least one diseased plant) and/or entire fields ('complete diseased mat uprooting', CDMU), followed by destruction of plant debris by burning, composting or burying, disinfection of farm tools between plants or after use on infected plants, early removal of male buds using a forked stick to prevent disease transmission by insect vectors, and use of clean planting materials (Karamura et al. 2008). Despite the promotion of these practices, XW continued to spread to new areas. Incomplete adoption of control practices by small-holder farmers has been identified as the major cause for the failed disease containment, due to the labour requirements and costs of uprooting entire diseased mats (Tushemereirwe et al. 2006; Bagamba et al. 2006; Jogo et al. 2013). Furthermore, CDMU results in significant yield reduction for up to 2 years due to the need to replant with healthy plants, which negatively affects food security and income of smallholder farmers (Jogo et al. 2013; Ocimati et al. 2013; Rietveld et al. 2014). Thus, determination of more efficient control strategies for XW was imperative.

Epidemiological studies of XW showed that Xvm does not colonize all lateral shoots within a diseased banana mat, a concept referred to as incomplete systemicity (Ocimati et al. 2013, 2015). The concept of incomplete systemic spread of Xvm gave rise to the practice of Single Diseased Stem Removal (SDSR), where only the symptomatic stems within an affected banana mat are removed, coupled with proper disposal of infected plant debris, sterilisation of garden tools and early removal of male buds (Blomme et al. 2014, 2019; Blomme et al. 2017b). In contrast to CDMU, SDSR has reduced labour need and less cost for implementation, and the yield losses that arise from losing all plants on a banana mat is averted. SDSR has been shown to reduce the incidence of XW to less than $2 \%$ within 3 months, irrespective of the initial incidence in pilot experiments in the eastern Democratic Republic of Congo (Blomme et al. 2019; Blomme et al. 2017b). In Uganda, a cost-benefit analysis to assess the adoption of the various elements of the SDSR package showed that the adoption of the full package resulted in financial benefits for farmers, with increases of approximately US\$ 462/ha/year (Kikulwe et al. 2019). 
In Rwanda, XW was first observed in Gisenyi province in 2002 (Reeder et al. 2007), and rapidly spread to all banana-producing regions of the country. The initial control strategy for XW was eradication (2005 to 2011) and was implemented through a government policy in Rwanda. Eradication focused on rogueing of complete plots and fields with diseased banana mats (CDMU), followed by planting annual crops (including maize and beans) for a period of at least one year (Rutikanga et al. 2016). Replanting with a selection of high-yielding banana cultivars (e.g., 'Mpologoma' [cooking; Musa AAA-EAH], 'Injagi' [cooking; Musa AAA-EAH], 'FHIA17' [tetraploid hybrid] and 'FHIA25' [tetraploid hybrid]) was advocated. However, XW has since reappeared in previously rogued and replanted areas (Gaidashova, personal communication, 2018; Okonya et al. 2019).

Landscape-wide rogueing has had a negative impact on the diversity of banana cultivars as only a limited selection of high yielding cultivars has been used as replants. CDMU continues to be promoted for control of XW. As in other affected countries of the region (Blomme et al. 2014; Jogo et al. 2013), the adoption of CDMU in Rwanda has been poor, with farmers often removing only the visibly diseased stems (Gaidashova, S. personal communication, 2019). Thus, determining SDSR as an alternative to CDMU in the agroecological zones of Rwanda where banana is cultivated is crucial to inform policy making for control of XW.

The objective was to determine whether SDSR and CDMU were preferable based on control of XW and the economics of the control measures under Rwandan agroecological conditions. Thus, we compared SDSR and CDMU for i) efficacy of XW control, and ii) impact on local farmers with respect to labour requirements and associated costs. We believe that the results will further guide XW control efforts across the ECA region.

\section{Materials and methods}

\section{Study area}

In January 2019, field experiments comparing SDSR and CDMU were initiated at four sites in Rwanda. Each site was in a different province, thus providing a range in agroecological factors for assessing the effectiveness of the two XW control approaches. The study sites were in the districts of Kayonza, Gisagara, Rubavu and Rulindo, respectively located in the Eastern, Southern, Western and Northern provinces of Rwanda (Fig. 1 and Table 1). The study region was situated within the equatorial zone and is characterised by a moderate tropical climate due to elevation (Henninger 2013; Peel et al. 2007). Further site description (climate and soil characteristics) is provided in Table 1.

\section{Experiment design}

At each site, fields/plots with at least 50 banana mats and an incidence of plants exhibiting symptoms of XW ranging from 3.5 to $9.4 \%$ were selected for the experiments. Plots with a similar initial plant incidence of XW, but to which no treatments were applied, were included as controls (as reference for comparison to the SDSR/ CDMU treatments). Banana mats consisted of one main stem and 2 to 3 suckers (lateral shoots that are physically connected to the main stem). In regard to mats, a mean of $19.5 \%$ of mats had symptoms of XW, with 12 to $33 \%$ of plants infected per mat. Additional plots with healthy plants (no symptoms of XW) were included as healthy controls. The two controls are referred to as the 'diseased control' and the 'healthy control'. The banana fields were comprised of a mixture of cultivars (dominated by AAA East African Highland types) and a mixture of young (planted within the past year) and mature (> 18 months) mats.

The CDMU treatment consisted of the immediate uprooting of entire diseased banana mats when at least one stem within a mat showed symptoms of XW. A hoe and/or a pickaxe were used for uprooting the mats. The mother plant and all attached lateral shoots, the underground corms and the roots within the upper $50 \mathrm{~cm}$ of soil and $60 \mathrm{~cm}$ laterally from the main banana stem were removed (Blomme 2000). Healthy suckers for replanting were sourced from fields with no prior history of XW within the trial village or district. Replanting was performed one month after removal to reduce yield losses that would have occurred if the recommended fallow period in Rwanda (6 to 12 months) was adhered to. Initially, Turyagyenda et al. (2007) and Sivirihauma et al. (2013) had recommended a 6- and 12-month fallow period, respectively, to allow all $X v m$ inoculum in the soil, and especially in remaining plant debris to be eliminated. However, subsequent field experience and insights into XW epidemiology showed that a shorter fallow period could also work, if all diseased mat rhizome pieces and roots were thoroughly removed. 


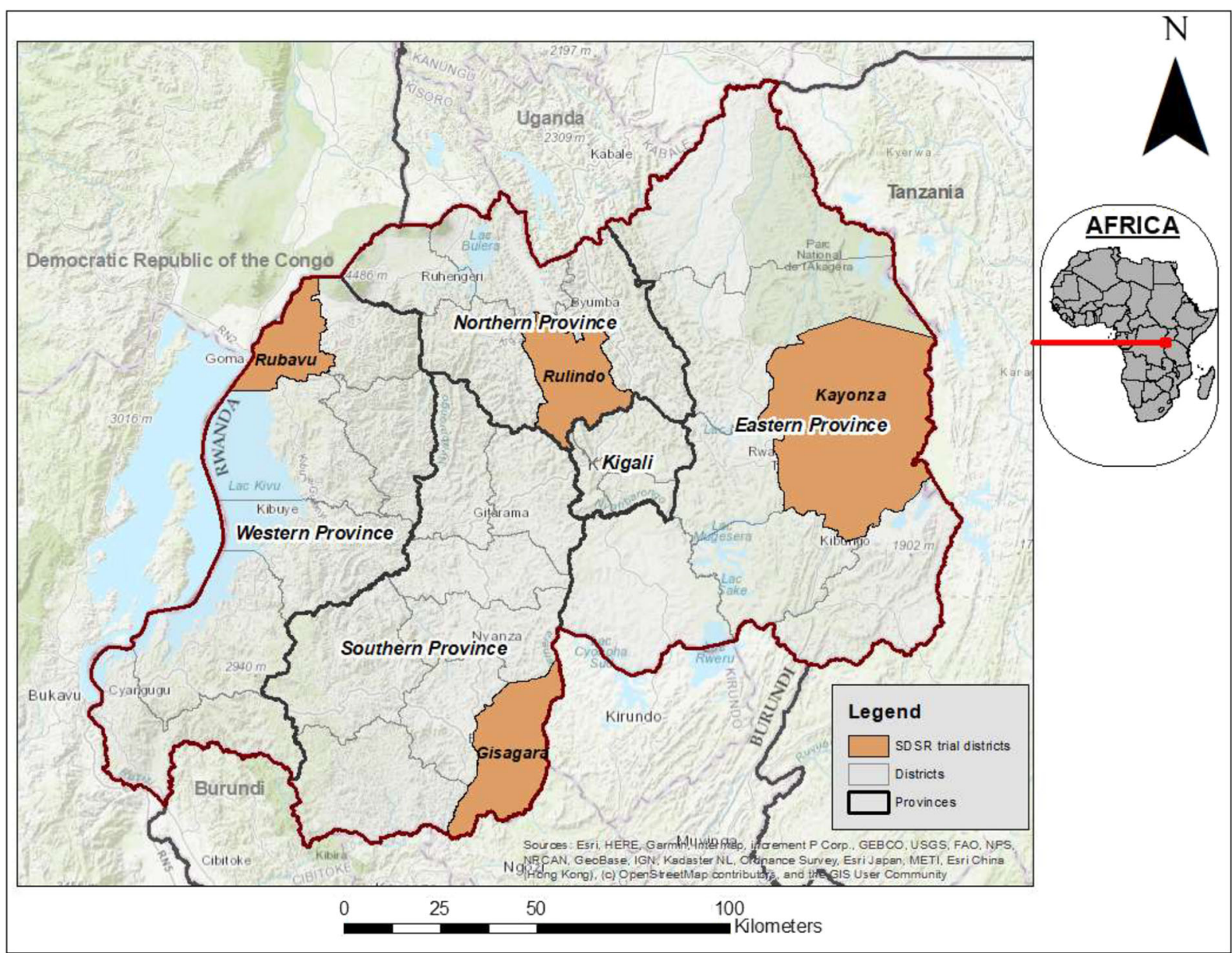

Fig. 1 Location of the four trial sites in the districts of Kayonza, Gisagara, Rulindo and Rubavu in Rwanda

Table 1 GPS coordinates, elevation, temperature, rainfall and edaphic descriptions for the four study sites in Rwanda

\begin{tabular}{|c|c|c|c|c|c|}
\hline $\begin{array}{l}\text { Site } \\
\text { name }\end{array}$ & $\begin{array}{l}\text { GPS } \\
\text { Coordinates }\end{array}$ & $\begin{array}{l}\text { Altitude } \\
\left(\text { masl }^{\mathrm{a}}\right)\end{array}$ & $\begin{array}{l}\text { Average annual } \\
\text { temperature }\left({ }^{\circ} \mathrm{C}\right)\end{array}$ & Annual rainfall (mm) & Soil type and characteristics \\
\hline Rubavu & $\begin{array}{l}01^{\circ} 6^{\prime} \mathrm{S}, 029^{\circ} \\
28^{\prime} \mathrm{E}\end{array}$ & 1481 & 18.1 & $\begin{array}{l}1377 \text { (https://www.weather-atlas. } \\
\text { com/en/rwanda/rubavu) }\end{array}$ & $\begin{array}{l}\text { Shallow Andosols made up of } \\
\text { weathered volcanic ash and lava. }\end{array}$ \\
\hline Kayonza & $\begin{array}{l}02^{\circ} 2.36^{\prime} \mathrm{S} \\
030^{\circ} 32.17^{\prime} \mathrm{E}\end{array}$ & 1557 & 22 & $\begin{array}{l}1100 \text { (Kayonza District Potentialities, } \\
2013 \text { ) and a bimodal rainfall pattern }\end{array}$ & $\begin{array}{l}\text { Mixed patches of Oxisol and } \\
\text { Ultisol and is predominantly } \\
\text { clay and sand with some } \\
\text { proportion of stones (UPCE } \\
\text { Consult 2012). }\end{array}$ \\
\hline Gisagara & $\begin{array}{l}2^{\circ} 36^{\prime} \mathrm{S} \\
028^{\circ} 54^{\prime} \mathrm{E}\end{array}$ & 1592 & 19.4 & $\begin{array}{l}1142 \text { (https://www.weather-atlas. } \\
\text { com/en/rwanda/Gisagara). }\end{array}$ & $\begin{array}{l}\text { Dominated by Oxisol, which is a } \\
\text { clay soil derived from shale } \\
\text { (Minema 2019; Verdoodt and } \\
\text { Van Ranst 2003). }\end{array}$ \\
\hline Rulindo & $\begin{array}{l}01^{\circ} 39^{\prime} \mathrm{S} \\
029^{\circ} 54^{\prime} \mathrm{E}\end{array}$ & 1792 & 16.5 & $\begin{array}{l}1326 \text { (Project brief Rulindo substation } \\
\text { and transmission lines 2011). }\end{array}$ & $\begin{array}{l}\text { Predominantly Ultisol and lateritic } \\
\text { (Verdoodt and Van Ranst 2003). }\end{array}$ \\
\hline
\end{tabular}

${ }^{\mathrm{a}}$ Meters above sea level 
Mwebaze et al. (2006) reported $X v m$ to have limited survival of less than 3 months in the soil in the absence of suitable host tissue (roots, corm pieces). To avoid possible contact with any remaining $X v m$ in the soil, the clean sucker was re-planted adjacent $(30-40 \mathrm{~cm})$ to the location of the uprooted diseased mat.

The SDSR treatment was implemented by carefully cutting diseased stems at soil level (just above the corm using a machete) without injuring other plants on the mat, at first sight of symptoms and where necessary, destroying apical meristems of the vegetative stage stems using a machete. The remaining apparently healthy banana plants were left on the mat, and thus replanting was not necessary.

The CDMU and SDSR treatments were both supplemented with: i) tool sterilization after cutting and uprooting all diseased mats (CDMU) and cutting single diseased stems (SDSR) in a plot, or when moving between treatment and control plots, and ii) removal of male flower buds on healthy plants using forked wooden sticks after formation of the last hand on the bunch. Disinfection of tools was performed by holding the metal blade in a fire. Within a treatment plot, no disinfection of the digging or cutting tools was done when moving between diseased banana plants/mats. Finally, all diseased plant material cut or uprooted in the treatment plots was transported to the edge of the banana field, chopped up and deposited in a manure/compost pit. All tools were disinfected after completing the task.

At each of the four locations, experiments were established on five to seven farms depending on the size of the XW infected fields. At each site, four replicate plots each consisting of 50 banana mats were used for each treatment, making a total of 16 plots per site. The treatment plots with CDMU and SDSR were adjacent to each other. Diseased control plots were located at least 100 to $500 \mathrm{~m}$ from the CDMU/SDSR treatment plots to avoid cross-infection. The healthy control plots were located at least 200 to $1000 \mathrm{~m}$ from any diseased plot. Across all locations and treatments, and during the entire duration of the trials, harvesting of individual mature plants was allowed/continued, while weeding and de-leafing was suspended to minimise the risk of tool-mediated transmission of the disease. Debudding (removal of the male inflorescence using a forked stick) to prevent insect-mediated transmission, was performed in all treatments, except in the diseased control plots. Limited de-suckering was conducted in some plots, using sterilized cutting tools and under close supervision of a field technician in order to prevent any disease spread.

\section{Data collection}

The number of mats per plot, the number of plants in each mat, the number of diseased mats, and the number of diseased plants per mat were recorded. All the treatment and control plots were closely monitored on a weekly basis over a 13-month period between January 2019 and February 2020. The removal of diseased plants or mats in, respectively, the SDSR or CDMU plots was done immediately after a diseased plant was spotted. A trained farmer recruited within the village and a competent data collector recommended by the village chief, performed plot management activities and data collection, respectively. Both were supervised by a qualified scientist.

The impact of both treatment practices on yield potential was assessed based on the number of plants removed with either practice or lost due to disease in the diseased control plots, within the initial 6-month period of the trials. The disease was reduced to a very low incidence in both the SDSR and CDMU treatment plots and the percentage of cumulative plants lost was used as a proxy for the loss of potential bunch-bearing banana plants.

To quantify the time- and cost-effectiveness of the two treatments, the total time and costs invested in the application of the control practices over the entire trial period were recorded. More specifically, for the SDSR treatment the time to cut each single diseased stem was recorded, while for the CDMU treatment, the time needed for uprooting each entire mat was recorded. Mean values were calculated from all cut plants or uprooted mats, respectively. For the latter, the additional time needed for replanting a healthy sucker after uprooting each mat was recorded. Time needed for the destruction/processing of each diseased plant or mat debris and transport to a compost heap were also recorded and added to time needed for the SDSR or CDMU treatments, respectively. The cost (in Rwandan francs [Frw]) of the practices included the labour for cutting or uprooting, destruction of the diseased plant material, replanting and the cost of healthy suckers for replanting (in the case of CDMU) was calculated. The time and cost for de- 
budding male flowers on healthy plants and mats was also included.

Data analysis

Prior to analysis, the residual plots were checked for deviations from linearity, homoscedasticity or normality. The percentage of plants lost due to Xanthomonas wilt $(\mathrm{XW})$, treatment time, and treatment cost were analysed using a one-way analysis of variance to determine treatment effects. A post hoc Tukey HSD test was used for mean separation $(\alpha=0.05)$ of the four treatments. Simple linear regression, with time as the independent variable and incidence of XW as the dependent variable, were performed to assess the progress of XW in the diseased control plots over the one-year trial period. The analyses were performed using the Rpackages 'stats' (R Core Team 2018) and 'agricolae' (Fde Mendiburu 2020), while post-processing and plotting was performed using the 'tidyverse' ecosystem (Wickham et al. 2019), 'dplyr' (Wickham et al. 2020) and 'ggthemes' (Arnold 2019) packages.

\section{Results}

Treatment effects on the incidence of XW

Both CDMU and SDSR were effective in reducing the incidence of XW (Fig. 2). Over all sites, incidence of XW declined significantly from $6.2 \%$ (standard deviation, $\mathrm{sd}=2.5)$ for the CDMU, and $7.0 \%(\mathrm{sd}=1.1)$ for the SDSR treatments, respectively, to $0.3 \%(\mathrm{sd}=0.2)$ and $0.7 \%(\mathrm{sd}=0.4)(\mathrm{F}=22.5, p<0.001$ and $\mathrm{F}=65.75$; $\mathrm{p}<0.001$, respectively) within one month after the experiment commenced. After the initial decline, incidence of XW remained below $1 \%$ for both treatments over all sites. Continued management by both CDMU and SDSR during the consecutive months proved to be necessary and effective.

In the diseased control plots (plots in which the diseased banana plants were left untreated) the incidence of XW remained high or increased over the duration of the trial over all the sites (Fig. 2).

The relationship between time and incidence of XW was dependent on location, and ranged from moderate to weak: Gisagara $\left(\mathrm{R}^{2}=0.49 ; \mathrm{F}=13.48, \mathrm{p}<0.001\right)$, a Gisagara

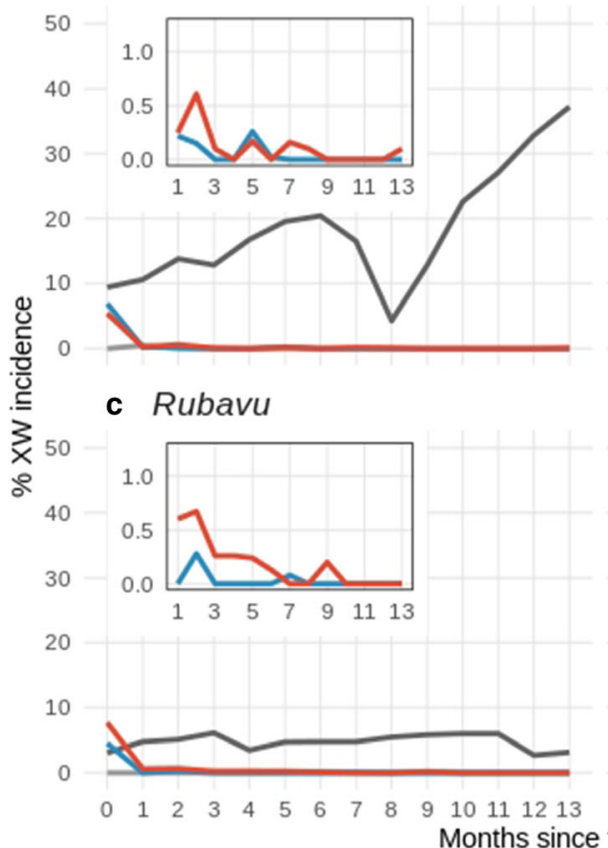

Fig. 2 Progress in the incidence of banana plants with symptoms of Xanthomonas wilt (XW) during a one-year trial in banana fields treated by complete diseased mat uprooting (CDMU) or by single diseased stem removal (SDSR) and in healthy and diseased control fields in (a) Gisagara, (b) Kayonza, (c) Rubavu, and (d) Rulindo.

\section{b Kayonza}

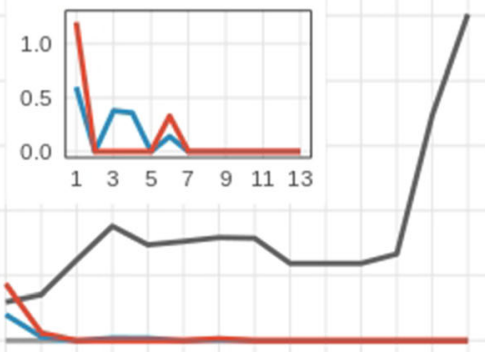

Treatment
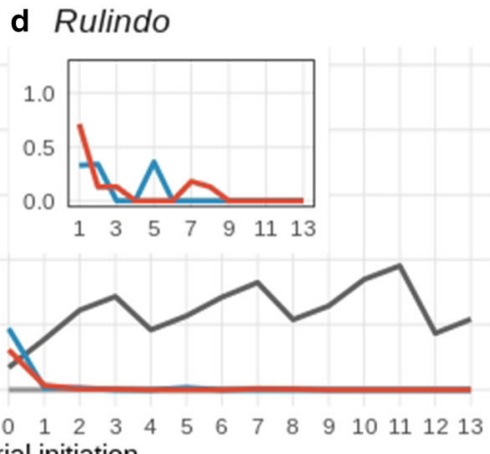

- Healthy control

- Diseased control

- $\mathrm{CDMU}$

- SDSR

Time 0 represents the initiation of the trials in January 2019, with disease progress shown in consecutive months since trial initiation. The inset figures present small fluctuations (0 to $1 \%$ ) in the incidence of XW commencing one month after trial initiation 
Kayonza $\left(\mathrm{R}^{2}=0.37 ; \mathrm{F}=8.76, p<0.05\right)$ and Rulindo $\left(\mathrm{R}^{2}=0.15 ; \mathrm{F}=3.21, p>0.05\right)$ in the diseased control plots. The incidence of XW in diseased controls increased from 9 to $37 \%, 6$ to $50 \%$ and 3.5 to $11 \%$ in Gisagara, Kayonza and Rulindo, respectively. At Rubavu, there was no significant increase in incidence of XW in the diseased control: the incidence of XW was approximately constant at $4.7 \%(\mathrm{sd}=1.2)$.

Despite the effectiveness of both treatments (Fig. 2 ), the average time to the point no diseased banana plants were observed in the treated plots was shorter for the CDMU treatment compared to the SDSR treatment (Fig. 3). Time to no visibly diseased plant for the CDMU treatment was 6 to 8 months, depending on site, and was not dependent on the initial disease incidence. Although the time to no diseased plants for the SDSR treatment fell within the range observed for the CDMU treatment at Kayonza (7 months), longer recovery times of 9 to 10 months were recorded at Rubavu and Rulindo, while fields at Gisagara were not fully recovered $(0.1 \% \mathrm{XW})$ at end of the trial (13th month), despite a low initial incidence of XW at the site. At all sites in treated plots, $\mathrm{XW}$ re-emerged periodically during the experiments (Fig. 2, inset plots). With the healthy control plots, only one plant at Gisagara developed symptoms of $\mathrm{XW}$ (one month after the experiment was commenced). The plant was removed. No further symptoms of XW developed on plants in any healthy control plots.
Impact of XW on productivity

Whilst both XW treatments effectively reduced disease incidence, the removal of single diseased stems (SDSR), or complete mats (CDMU) resulted in thinning of mats or mats in the fields, respectively, and thus reduced productivity. The cumulative number of stems removed over the initial 6-month period was significantly lower $(\mathrm{F}=20.35, p<0.001)$ for SDSR compared to the CDMU treatment (Fig. 4). Over all sites, $15 \%$ (6 to $29 \%$ ) of the plants at the start of the trial were removed by the SDSR treatment compared to $35 \%$ (12 to $70 \%$ ) for the CDMU treatment. During this initial 6-month period, the number of plants removed applying the CDMU treatment was comparable to a mean stem loss of $29 \%$ (7 to 64\%) in the diseased control plots.

Some variability was observed in the proportion of stems lost between study sites. For example, there was no differences in the percentage of stems lost using the SDSR or CDMU treatments and the diseased control plots at Rulindo (Fig. 4d). This is due to the high within-site variability in the incidence of XW in the CDMU plots. At Rubavu (Fig. 4c), there was a significant difference $(\mathrm{F}=16.15, p<0.01)$ between the SDSR and CDMU treatments in the number of stems removed, while a limited number of stems were lost in the diseased control plots. At Rubavu there was a persistent low incidence of XW in the diseased control plots during the entire experiment (Fig. 4c), possibly due to the initial low incidence in these plots (Fig. 2).
Fig. 3 The time to eradication of Xanthomonas wilt (XW) in banana fields in Rwanda with different initial incidence of XW. Blue dots denote Complete Diseased Mat Uprooting (CDMU), while red dots denote Single Diseased Stem Removal (SDSR). The dots show the point at which no more diseased plants were observed for the remainder of the treatment period, while a cross denotes ongoing presence of XW disease at the end of the trial

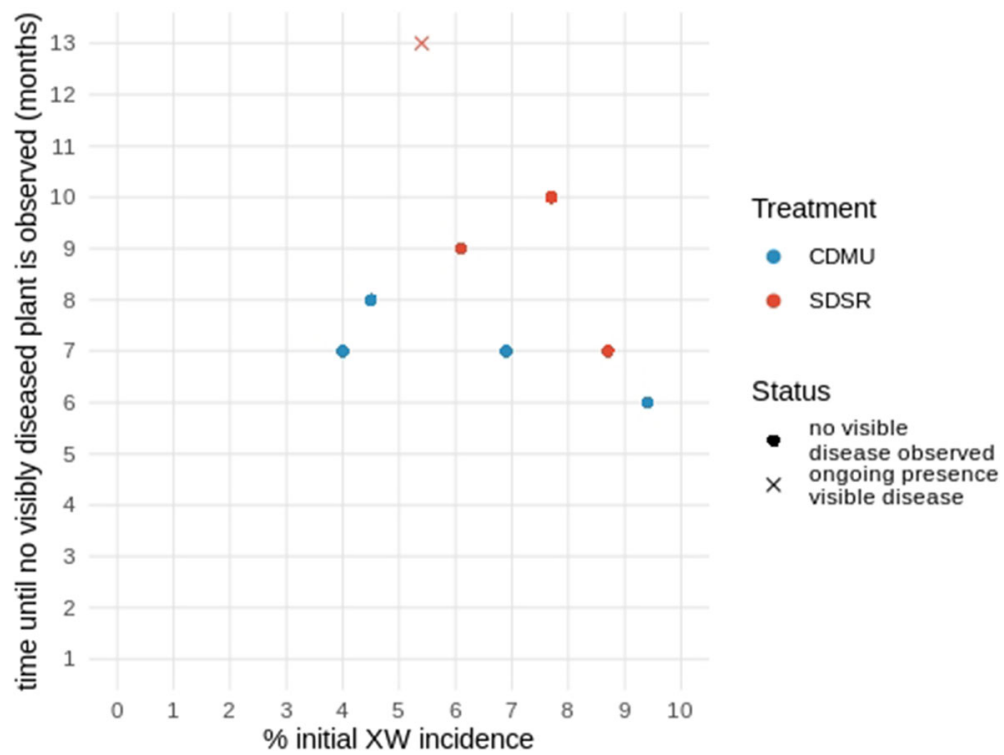


Fig. 4 Percentage of plants lost due to Xanthomonas wilt (XW) over the initial 6-month period of the experiment in the Complete Diseased Mat Uprooting (CDMU) treatment plots, the Single Diseased Stem Removal (SDSR) treatment plots and the diseased control plots. During the first 6 months of the experiment the incidence of $\mathrm{XW}$ was reduced to very low values for both the CDMU and the SDSR treatments. Statistical differences between treatments within sites are indicated by different letters according to Tukey's HSD test $(\alpha=$ 0.05 ). Whiskers indicate standard errors of the means

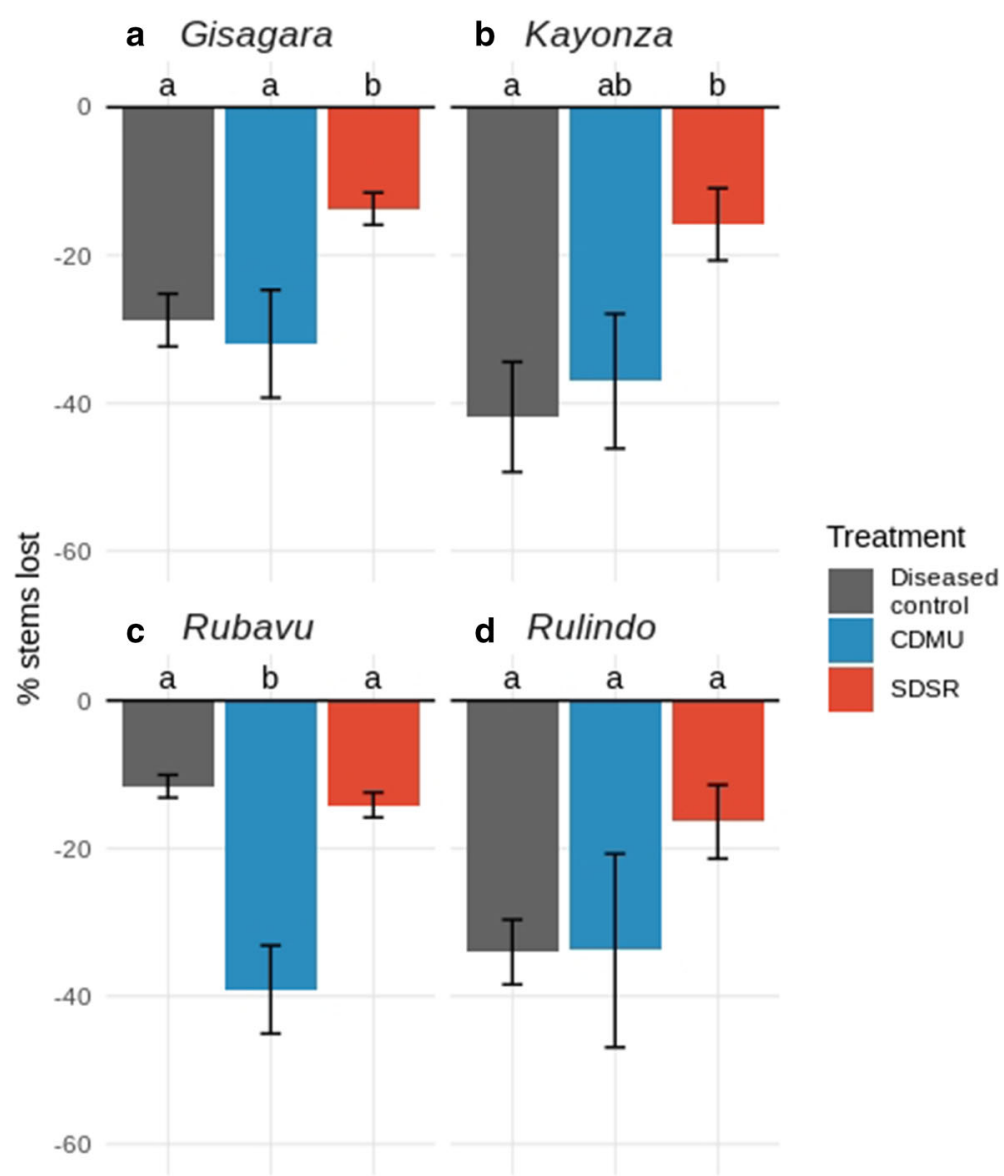

At Gisagara and Kayonza, the SDSR treatment was more productive than the CDMU and the diseased control treatments (Kayonza: $\mathrm{F}=8.22, p<0.05$; Gisagara: $\mathrm{F}=10.77, \mathrm{p}<0.05)$. Over all sites combined, the SDSR treatment consistently had a lower proportion of cut plants.

\section{Labour and cost of XW control options}

The SDSR treatment required less time and cost compared to the CDMU treatment for control of XW (Tables 2 and 3). Time needed for the removal of a single plant using SDSR was significantly less $(0.4 \mathrm{~min}, \mathrm{sd}=0.2)$ compared to uprooting an entire banana mat using CDMU (15.8 $\mathrm{min}, \mathrm{sd}=4.4)(\mathrm{F}=$ $117.2, p<0.001)$. The time needed to uproot a diseased mat was significantly different between sites $(\mathrm{F}=3.79$, $\mathrm{p}<0.05)$; mat removal took $10.1 \mathrm{~min}(\mathrm{sd}=4.4)$ at Gisagara compared to an average of $17.7 \mathrm{~min}(\mathrm{sd}=$ 2.8 ) at the three other sites, Kayonza, Rulindo and Rubavu, combined. The difference in time is likely due to a difference in banana cultivars and the size of the mats. The time to remove a single plant (SDSR) was similar across sites. The time taken to move and destroy (move plant debris to a compost heap) an entire infected banana mat (7.4 min, $\mathrm{sd}=1.2$ ) was significantly higher $(\mathrm{F}=78.11, \mathrm{p}<0.001)$ than for a single plant $(3.8 \mathrm{~min}$, $\mathrm{sd}=0.2$ ). For CDMU, an additional time of $13.6 \mathrm{~min}$ $(\mathrm{sd}=1.0)$ was needed for replanting. No replanting was needed using SDSR. Including all activities, the total time needed was $4.2 \mathrm{~min}(\mathrm{sd}=0.3)$ for the SDSR treatment and $36.4(\mathrm{sd}=4.4)$ for the CDMU treatment.

The total cost for each treatment (the labour cost of uprooting a mat or cutting a stem, diseased plant or mat destruction, plus the cost of healthy plant material and replanting in the case of CDMU) followed a similar pattern to time needed (Table 3). On average, the total cost of the SDSR treatment per plant was 25 Frw $(s d=2)$, while the CDMU treatment cost 619 Frw $(s d=27)$ per mat. The total cost of CDMU was significantly $(\mathrm{F}=4.07, p<0.05)$ lower at Gisagara (581 Frw, sd $=27$ ) compared to the other three sites 
Table 2 Time required for treatments to control Xanthomonas wilt (XW) of banana in Rwanda. The Complete Diseased Mat Uprooting (CDMU) treatment and the Single Diseased Stem Removal (SDSR) treatment are standardized to one mat or plant, respectively. Time (minutes) for complete uprooting of an entire mat, or cutting of a single stem, removal of male buds, destruction of diseased plant material and replanting of healthy suckers after diseased mat removal are presented

\begin{tabular}{|c|c|c|c|c|c|}
\hline \multirow[t]{2}{*}{ Site } & \multirow[t]{2}{*}{ Treatment } & \multicolumn{4}{|c|}{ Time per mat or plant $(\min )^{\mathrm{a}}$} \\
\hline & & Time uprooting / cutting & Time destruction & Time replanting & Total time \\
\hline \multirow[t]{2}{*}{ Gisagara } & CDMU & $10.1 \mathrm{c}\left(4.4^{\mathrm{b}}\right)$ & $8.0 \mathrm{a}(0.8)$ & 12.0 & $30.1 \mathrm{~b}(4.5)$ \\
\hline & SDSR & $0.2 \mathrm{~d}(0.1)$ & $4.0 \mathrm{c}(0.8)$ & 0 & $4.2 \mathrm{c}(0.8)$ \\
\hline \multirow[t]{2}{*}{ Kayonza } & CDMU & $17.0 \mathrm{ab}(2.0)$ & $8.5 \mathrm{a}(1.3)$ & 14.0 & $39.5 \mathrm{a}(2.0)$ \\
\hline & SDSR & $0.4 \mathrm{~d}(0.1)$ & $3.8 \mathrm{c}(1.0)$ & 0 & $4.1 \mathrm{c}(0.9)$ \\
\hline \multirow[t]{2}{*}{ Rubavu } & CDMU & $20.8 \mathrm{a}(2.6)$ & $5.8 \mathrm{~b}(1.0)$ & 13.0 & $39.5 \mathrm{a}(2.2)$ \\
\hline & SDSR & $0.4 \mathrm{~d}(0.2)$ & $3.5 \mathrm{c}(0.6)$ & 0 & $3.9 \mathrm{c}(0.5)$ \\
\hline \multirow[t]{3}{*}{ Rulindo } & CDMU & $15.4 b(7.3)$ & 7.5a (1.3) & 14.0 & $36.9 \mathrm{a}(7.0)$ \\
\hline & SDSR & $0.6 \mathrm{~d}(0.4)$ & $4.0 \mathrm{c}(0.8)$ & 0 & $4.6 \mathrm{c}(1.0)$ \\
\hline & $\mathrm{F}(\mathrm{P} \text { value })^{\mathrm{c}}$ & $4.45(0.014)$ & $2.13(0.127)$ & $5.60(0.001)$ & $5.36(0.007)$ \\
\hline
\end{tabular}

${ }^{a}$ Means in a column followed by the same letter are not significantly different from each other according to Tukey's HSD test ( $\left.p \leq 0.05\right)$

${ }^{\mathrm{b}}$ Standard deviations are provided in parentheses

${ }^{\mathrm{c}}$ The F-value (based on the F-distribution) is obtained from the analysis of variance, and the $P$ value is the probability of obtaining an F-value at least as extreme as that observed, assuming that the null hypothesis is correct

combined $(632 \mathrm{Frw}, \mathrm{sd}=9)$ due to a shorter labour time linked to smaller mat sizes.

A major portion of the total cost of CDMU was the new planting material (400 Frw per sucker, or

Table 3 Treatment cost for strategies to control Xanthomonas wilt (XW) of banana in Rwanda. The Complete Diseased Mat Uprooting (CDMU) treatment and the Single Diseased Stem Removal (SDSR) treatment are standardized to one mat or plant, respectively. Labour cost (Rwandese Franc; Frw) for complete approximately $65 \%$ of the total cost). The cost of labour needed for replanting was also significant $(80 \mathrm{Frw}$ [sd = 6], or approximately $13 \%$ of the total cost). Replanting was not necessary with the SDSR treatment. The labor

\begin{tabular}{|c|c|c|c|c|c|c|}
\hline \multirow[t]{2}{*}{ Site } & \multirow[t]{2}{*}{ Treatment } & \multicolumn{5}{|l|}{ Cost per mat or plant (Frw) ${ }^{a}$} \\
\hline & & Labour cost uprooting / cutting & $\begin{array}{l}\text { Labour cost } \\
\text { destruction }\end{array}$ & $\begin{array}{l}\text { Labour cost } \\
\text { replanting }\end{array}$ & $\begin{array}{l}\text { Cost planting } \\
\text { material }\end{array}$ & Total cost \\
\hline \multirow[t]{2}{*}{ Gisagara } & CDMU & $60.5 \mathrm{c}\left(26.3^{\mathrm{b}}\right)$ & 48.0a (4.9) & 72 & 400 & $580.5 b(26.7)$ \\
\hline & SDSR & $1.3 \mathrm{~d}(0.7)$ & $24.0 \mathrm{c}(4.9)$ & 0 & 0 & $25.3 \mathrm{c}(4.9)$ \\
\hline \multirow[t]{2}{*}{ Kayonza } & CDMU & 101.8ab (12.1) & $51.0 \mathrm{a}(7.8)$ & 84 & 400 & $636.8 \mathrm{a}(12.3)$ \\
\hline & SDSR & $2.2 \mathrm{~d}(0.6)$ & $22.5 \mathrm{c}(5.8)$ & 0 & 0 & $24.7 \mathrm{c}(5.6)$ \\
\hline \multirow[t]{2}{*}{ Rubavu } & CDMU & 124.5a (15.6) & $34.5 \mathrm{~b}(5.8)$ & 78 & 400 & 637.0a (12.9) \\
\hline & SDSR & $2.6 \mathrm{~d}(0.9)$ & $21.0 \mathrm{c}(3.5)$ & 0 & 0 & $23.6 \mathrm{c}(3.2)$ \\
\hline \multirow[t]{3}{*}{ Rulindo } & CDMU & $92.2 b(43.5)$ & $45.0 \mathrm{a}(7.8)$ & 84 & 400 & $612.2 \mathrm{a}(41.9)$ \\
\hline & SDSR & $3.9 \mathrm{~d}(2.6)$ & $24.0 \mathrm{c}(4.9)$ & 0 & 0 & $27.8 \mathrm{c}(5.9)$ \\
\hline & $\mathrm{F}(\mathrm{P} \text { value })^{\mathrm{c}}$ & $4.45(0.014)$ & $2.13(0.127)$ & $6.02(0.001)$ & $2.11(0.129)$ & $5.36(0.07)$ \\
\hline
\end{tabular}

\footnotetext{
${ }^{a}$ Means in a column followed by the same letter are not significantly different from each other according to Tukey's HSD test ( $\mathrm{p} \leq 0.05$ )

${ }^{\mathrm{b}}$ Standard deviations are provided in parentheses

${ }^{\mathrm{c}}$ The F-value (based on the F-distribution) is obtained from the analysis of variance, and the $\mathrm{P}$ value is the probability of obtaining an F-value at least as extreme as that observed, assuming that the null hypothesis is correct
} 
cost for an entire banana mat with the CDMU treatment ( $95 \mathrm{Frw}, \mathrm{sd}=27$ ) was on average 40 -fold higher than that for a single infected plant using the SDSR treatment (2.5 Frw, sd =1). The labour cost for destroying a diseased mat (45 Frw, sd $=7$ ) was approximately twice that for the destruction of a single plant ( $23 \mathrm{Frw}, \mathrm{sd}=1$ ).

De-budding of the remaining healthy flowering plants was performed for both the SDSR and CDMU treatment plants and took on average $0.07 \mathrm{~min}(\mathrm{sd}=$ $0.04)$ per plant for an average labour cost of 0.4 Frw $(\mathrm{sd}=0.3)$ over all sites combined.

\section{Discussion}

Effectiveness of CDMU and SDSR for control of XW

The results of the study show that both CDMU and SDSR similarly reduced the incidence of XW. The incidence of XW declined to less than $0.5 \%$ within 3 months of initiating the treatments. However, the incidence of XW in the disease control plots (no CDMU or SDSR applied) remained high or increased during the 13-month study period. The decline in incidence of XW and recovery of the plant population in the SDSR treated plots is consistent with the results of Blomme, Ocimati, et al. (2017b); Blomme et al. (2019). The time to complete recovery of fields from XW was shorter with the CDMU treatment compared to the SDSR treatment, which may be attributed to differences in the mechanism of the two approaches. With both approaches, the reduction in incidence of XW and recovery of plant populations in fields is attributed to removal of diseased plants and a reduction or elimination of $X v m$ inoculum, and in the case of the CDMU treatment, replanting. With the SDSR treatment the chance exists that, apart from the visibly diseased plant or plants in a mat that were removed, other stems within the physically interconnected mat may be infected with $X v m$ but as yet the disease is latent (Blomme et al. 2014; Blomme et al. 2017b,b; Ocimati et al. 2015). Incursions of Xvm into lateral shoots most often results in latent infections that do not jeopardize growth and yield of the banana plant (Ocimati et al. 2013, 2015). However, a limited number of plants with latent infections can still develop symptoms, although the time for symptom development is not predictable. Ocimati et al. $(2013,2015)$ reported long incubation periods for XW (up to 24 months) in lateral shoots attached to mother plants that had been artificially inoculated through the inflorescence. Latency could also explain the outbreaks of XW that we observed after periods where no XW was observed in either the SDSR- or CDMU-treated plots (Fig. 2). The outbreaks of XW underline the need for regular assessments for XW in fields managed with SDSR, whether in the early stages of control or when there is no visible evidence of XW remaining, as small outbreaks are likely to occur at irregular intervals over a period of many months. In addition, Ntamwira et al. (2019) reported that timely application of SDSR (immediately after observing first symptom) was more effective for field recovery compared to a delayed application ( 2 weeks and 4 weeks) or no SDSR application. Timely application of SDSR not only reduces XW inoculum in diseased mats, it also prevents potential infection and/or build-up of $X v m$ in lateral shoots physically attached to the diseased plant. With CDMU, it is important to replant using clean planting materials. The additional components of both SDSR and CDMU, i.e., the early removal of male buds and the sterilization of farm tools most likely played an important role in preventing within mat and within field spread. If applied area-wide, both XW management approaches will reduce introductions from external sources through insect vectors, contaminated farm tools, or diseased planting material.

This study was conducted on farmers' fields, and the history of XW management in the plots was not available. It is possible that $\mathrm{XW}$-management activities prior to the experiments could have influenced to the recovery of plant populations in experiment plots. However, this is unlikely when comparing the results from the control and treated plots at the different sites.

Impact of CDMU and SDSR on productivity

If left untreated, XW severely reduces banana production. Across the study sites in the diseased control plots there was a $29 \%$ reduction in productive banana plants over the 6-month period after trial initiation; the reduction in productive banana plants continued for the duration of the experiment. Other studies in the ECA report potential banana yield losses of up to $100 \%$ due to XW (Ssekiwoko et al. 2006; Kagezi et al. 2006; Tushemereirwe et al. 2006). It should be noted that other field operations including weeding, de-budding and deleafing were halted for the duration of the trial in the diseased control plots. Limited de-suckering was performed in the diseased control plots at Rubavu under 
close supervision of a field technician. Banana harvesting was conducted in all diseased control plots.

CDMU required uprooting entire mats comprised of symptomatic and asymptomatic plants which contributes to high yield losses. Potential yield loss in the CDMU plots, measured as mean number of plants lost or rogued in the 6 months after trial initiation, was $6 \%$ and $20 \%$ higher compared to that observed in the diseased control (29\%) and the SDSR (15\%) plots, respectively. The time needed to restore pre-infection yield levels using CDMU can be 18 to 20 months at the midto high-altitude sites in the ECA (Blomme et al. 2014). This prolonged recovery is attributed to the short fallow period between uprooting and replanting, and the time needed for a young sucker to grow into a mature plant (up to 18 months from planting to harvest). With the SDSR treatment, a mean of $15 \%$ of plants were removed, but because the banana mat was not removed, the remaining apparently healthy plants contributed to final yield. Thus, yield losses are lower using SDSR compared to CMDU, or to not applying any control measure. After applying CDMU, it is important to replant using clean planting materials.

Time and cost-efficiency

SDSR was more time and cost-efficient compared to CDMU. Using SDSR compared to CDMU reduced time to control XW by $88 \%$ and the cost of control by $96 \%$. As expected, the cutting and disposal of single diseased plants by SDSR was less time consuming, less labour intensive and less costly. No additional time or cost related to replanting were incurred with SDSR. With CDMU, mats comprised of several plants had to be completely uprooted and disposed of. New, healthy planting materials had to be acquired and planted, leading to additional costs.

Rapid progress in XW is observed when sources of inoculum were not removed in a timely manner, when male buds are left on the plants, and garden tools used for de-leafing, de-budding, de-suckering and other farm operations are not sterilized after use (Blomme et al. 2017a, b; 2019; Ntamwira et al. 2019). So, both time and cost are also associated with the additional XW control operations of early de-budding of the male inflorescence part on healthy plants, and the sterilisation of tools. Both activities are crucial to prevent spread of XW under both SDSR and CDMU. With CDMU there may initially be fewer plants to de- bud due to the uprooting of whole mats (comprising sick and healthy plants) and a delay in de-budding of the newly planted suckers. The overall difference in time and cost for de-budding between the two control practices is however expected to be minimal. Thus, the time and associated costs for both de-budding and tool sterilisation are not expected to affect the adoption of either management practice.

\section{Reflections on adoption of CDMU and SDSR}

Notwithstanding the importance of banana as a food and income source in the ECA, reports indicate that CDMU has been poorly adopted (Blomme et al. 2014; Jogo et al. 2013; Ocimati et al. 2019), which is thought to be due to the high labor demand and cost of CDMU. Blomme et al. (2017b) reported better adoption of CDMU in the marketoriented production systems (e.g. of south-western Uganda) compared to the subsistence-oriented production systems (e.g. of central Uganda). Kikulwe et al. $(2018,2019)$ reported that 'small' banana farmers have a low return on investment from XW control measures and is thus a reason why adoption is low in Uganda. Subsistence farmers dominate in the ECA, including in Rwanda, and SDSR is a suitable alternative to CDMU for the region. Adoption of agricultural innovations and disease control measures is dependent on multiple factors. These include the complexity of the proposed technique, compatibility with ongoing activities, the associated risks, the performance of the new technology and cultural and normative appropriateness (Sinja et al. 2004; Doss 2006; Pircher et al. 2013).

Adoption of XW control practices may also be influenced by gender relations and norms within households and communities. Kikulwe et al. (2018, 2019) found that women in male-led households had a lower adoption of XW control measures compared to their male partners. Since the authors did not differentiate between CDMU and SDSR, it is impossible to draw conclusions between control methods. However, Iradukunda et al. (2019) observed that labor constraints of women in female-led households limits their adoption of SDSR practices, and gender norms played a role in Burundi. For instance, norms that prescribe certain managerial tasks like digging and cutting the stems to be performed by men only (Rietveld and Farnworth 2018a, b; Kawarazuka et al. 2020) also affect adoption of control practices among women. Such norms can affect the adoption of both CDMU and SDSR. One aspect which is often ignored in adoption studies is the emotional component. Unlike 
annual crops, or even some fruit trees, banana plantations in the ECA region tend to be long-lived. In a study conducted in Uganda (Kilwinger et al. 2019), farmers claimed that so long as new suckers keep on generating, a banana plantation can survive indefinitely. As such, the banana plantation presents inter-generational value and security to farming households, and farmers often feel an attachment to their plantation, and even to individual mats of specific cultivars which they have been collecting and growing over decades. In addition, banana is associated with traditional beliefs, ceremonies and rituals and presents spiritual value; "the plantation is almost considered a living organism, which requires respect" concluded Kilwinger et al. (2019). Thus, applying CDMU and uprooting XW diseased banana mats may have a psychological toll on farmers, making them perceive the control method as destruction rather than rescue. Access to healthy planting material may be an additional limiting factor to banana farmers in the ECA region; most farmers rely on suckers from their own or a neighbor's farm. Such suckers are potential sources of Xvm, or other pests and pathogens, thus perpetuating the problem.

Following these lines of reason, SDSR which is less destructive may be perceived as a more 'normal' and acceptable banana disease management technique in the sense that it prescribes only slight alterations to a common practice of cutting stems, irrespective of the associated labor and costs investment. However, when XW first appears on a new farm, and only a hand-full of mats are infected, the application of CDMU might be advised as it offers a greater probability to fully eradicate the disease. But, once the disease has spread over a larger geographical area and many banana mats are diseased, eradication becomes impossible and SDSR is the most rational approach.

\section{Conclusions on adoption of XW control options}

This is the first report quantifying and contrasting the time and labor demands associated with CDMU and SDSR. The results show CDMU and SDSR are effective at reducing the incidence of XW in banana farms over short periods, although production recovered more rapidly under SDSR. CDMU is associated with a large production loss over a long period, high labor and time costs, and a cost of replanting with healthy young plants. The costs and time needs are either lower or nonexistent with SDSR. The evidence we present confirms
SDSR as the easier and cheaper control option for XW and explains the poor adoption of CDMU in the ECA. Based on these results, the SDSR package should be more widely accepted and adopted by farmers and policy makers in Rwanda, resulting in its promotion and acceptance as a superior alternative to the currently advocated CDMU. In addition, the results provide additional insights for countries or regions where SDSR is already widely practised.

Acknowledgments We are grateful for the support of our project partner, The Rwanda Agriculture and Animal Resources Board (RAB) for a continued facilitation and technical support all along demo trial establishment, data collection and analysis, and paper writing. This research was funded by the CGIAR Research Program on Roots, Tubers and Bananas through the SDSR scaling project in east and central Africa, and the CGIAR Fund Donors (http://www.cgiar.org/about-us/our-funders/).

Authors' contributions Guy Blomme and Walter Ocimati conceived and developed the research concept, contributed to data analysis, and contributed to writing and editing the manuscript.

Petronille Dusingizimana and Jules Ntamwira contributed to the development of the research concept, led and conducted the field trials, analysed the data, and contributed to manuscript writing.

Svetlana Gaidashova contributed to the field trials, and data and result interpretation.

Elizabeth Kearsley supported data interpretation, and the writing and editing of the manuscript.

Anne Rietveld contributed to writing and editing of the manuscript and managed the SDSR Scaling Fund project in east and central Africa.

Boudy Van Schagen contributed to conceiving the research concept and managed the SDSR Scaling Fund project in east and central Africa.

Funding This study was supported by funds from the CGIAR Research Program on Roots, Tubers and Bananas through the SDSR scaling project in east and central Africa, and the CGIAR Fund Donors (http://www.cgiar.org/about-us/our-funders/). This work received financial support from the German Federal Ministry for Economic Cooperation and Development (BMZ) commissioned and administered through the Deutsche Gesellschaft für Internationale Zusammenarbeit (GIZ) Fund for International Agricultural Research (FIA), grant number: 81219434

Data availability (data transparency) Data can be made available.

Code availability (software application or custom code) Not applicable.

Declarations Ethical issues could have arisen from the establishment of diseased control plots in which Xanthomonas wilt of banana was not managed. To mitigate the problem, farmers were 
compensated for potential losses in food and or income due to nonmanagement of the disease on their fields.

\section{Research involving human participants and/or animals Not applicable.}

Informed consent Not applicable.

Disclosure of potential conflicts of interest The authors declare that the research was conducted in the absence of any commercial or financial relationships that could be construed as or result in a potential conflict of interest.

Open Access This article is licensed under a Creative Commons Attribution 4.0 International License, which permits use, sharing, adaptation, distribution and reproduction in any medium or format, as long as you give appropriate credit to the original author(s) and the source, provide a link to the Creative Commons licence, and indicate if changes were made. The images or other third party material in this article are included in the article's Creative Commons licence, unless indicated otherwise in a credit line to the material. If material is not included in the article's Creative Commons licence and your intended use is not permitted by statutory regulation or exceeds the permitted use, you will need to obtain permission directly from the copyright holder. To view a copy of this licence, visit http://creativecommons.org/licenses/by/4.0/.

\section{References}

Arnold, J. B. (2019). ggthemes: Extra Themes, Scales and Geoms for 'ggplot2'. R package version 4.2.0. https://CRAN.Rproject.org/package $=$ ggthemes

Bagamba, F., Kikulwe, E., Tushemereirwe, W. K., Ngambeki, D., Muhangi, J., Kagezi, G. H., \& Eden-Green, S. (2006). Awareness of banana bacterial wilt control in Uganda: Farmers' perspective. African Crop Science Journal, 14(2), $157-164$.

Blomme, G. (2000). The interdependence of root and shoot development in banana (Musa spp.) under field conditions and the influence of different biophysical factors on this relationship. Ph.D. thesis $\mathrm{N}^{\circ}$ 421. K. U. Leuven. Faculty of Agriculture and Applied Biological Sciences. Belgium. pp. 183.

Blomme, G., Dita, M., Jacobsen, K. S., Pérez Vicente, L., Molina, A., Ocimati, W., Poussier, S., \& Prior, P. (2017b). Bacterial diseases of bananas and Enset: Current state of knowledge and integrated approaches toward sustainable management. Frontiers in Plant Sciences, 8, 1290. https://doi.org/10.3389 /fpls.2017.01290.

Blomme, G., Jacobsen, K., Ocimati, W., Beed, F., Ntamwira, J., Sivirihauma, C., Ssekiwoko, F., Nakato, V., Kubiriba, J., Tripathi, L., \& Tinzaara, W. (2014). Fine-tuning banana Xanthomonas wilt control options over the past decade in east and Central Africa. European Journal of Plant Pathology, 139(2), 271-287.
Blomme, G., \& Ocimati, W. (2018). Xanthomonas bacterial wilt. In: Chapter 5: Diseases caused by bacteria and phytoplasmas. Handbook of diseases of banana, abacá and enset. (Jones, D.R. (ed.)). Wallingford (UK) CAB international. Pp. 296313. ISBN: 9781780647197.

Blomme, G., Ocimati, W., Sivirihauma, C., Lusenge, V., Bumba, M., \& Ntamwira, J. (2019). Controlling Xanthomonas wilt of banana: Influence of collective application, frequency of application, and social factors on the effectiveness of the single diseased stem removal technique in eastern Democratic Republic of Congo. Crop Protection, 118, 79 88.

Blomme, G., Ocimati, W., Sivirihauma, C., Vutseme, L., Mariam, B., Kamira, M., van Schagen, B., Ekboir, J., \& Ntamwira, J. (2017a). A control package revolving around the removal of single diseased banana stems is effective for the restoration of Xanthomonas wilt infected fields. European Journal of Plant Pathology, 149(2), 385-400.

Buregyeya, H., Kubiriba, J., Tusiime, G., Kityo, R., Ssekiwoko, F., \& Tushemerierwe, W. K. (2014). Role of birds and bats in long distance transmission of banana bacterial wilt in Uganda. International Journal of Agricultural Innovations and Research, 2, 636-640.

Carter, B. A., Reeder, R., Mgenzi, S. R., Kinyua, Z. M., Mbaka, J. N., Doyle, K., Nakato, V., Mwangi, M., Beed, F., Aritua, V., Lewis Ivey, M. L., Miller, S. A., \& Smith, J. J. (2010). Identification of Xanthomonas vasicola (formerly $X$. campestris pv. musacearum), causative organism of banana Xanthomonas wilt, in Tanzania, Kenya and Burundi. Plant Pathology, 59, 403-403.

Castellani, E. (1939). Su un marciume dell' Ensete. L'Agricoltura Coloniale, Firenze, 33, 297-300.

de Mendiburu, F. (2020). Agricolae: Statistical procedures for agricultural research. $R$ package version, $1,3-3$ https://CRAN.R-project.org/package=agricolae.

Doss, C. R. (2006). Analyzing technology adoption using microstudies: Limitations, challenges, and opportunities for improvement. Agricultural Economics, 34, 207-219.

Eden-Green, S. J. (2004). How can the advance of banana Xanthomonas wilt be halted? InfoMusa, 13, 38-41.

Henninger, S. (2013). Does the global warming modify the local Rwandan climate? Natural Science, 5(1), 124-129. https://doi.org/10.4236/ns.2013.51A019.

Iradukunda, F., Bullock, R., Rietveld, A., \& van Schagen, B. (2019). Understanding gender roles and practices in the household and on the farm: Implications for banana disease management innovation processes in Burundi. Outlook on Agricultures, 48, 37-47. https://doi.org/10.1177 /0030727019831704.

Jogo, W., Karamura, E., Tinzaara, W., Kubiriba, J., \& Rietveld, A. (2013). Determinants of farm-level adoption of cultural practices for banana Xanthomonas wilt control in Uganda. Journal of Agricultural Science, 5, 70-82.

Kagezi, G. H., Kangire, A., Tushmereirwe, W., Bagamba, F., Kikulwe, E., Muhangi, J., Gold, C. S., \& Ragama, P. (2006). Banana bacterial wilt incidence in Uganda. African Crop Science Journal, 14, 83-91.

Karamura, E. B., Turyagyenda, F. L., Tinzaara, W., Blomme, G., Molina, A., \& Markham, R. (2008). Xanthomonas Wilt (Xanthomonas campestris pv. musacearum) of bananas in 
east and Central Africa. Diagnostic and Management Guide. Fountain Publishers, Kampala, Uganda.

Kawarazuka, N., Damtew, E., Mayanja, S., Okonya, J. S., Rietveld, A., Slavchevska, V., \& Teeken, B. (2020). A gender perspective on pest and disease management from the cases of roots, tubers and bananas in Asia and sub-Saharan Africa. Frontiers in Agronomy, 2, 7. https://doi.org/10.3389 /fagro.2020.00007.

Kayonza District Potentialities (2013). District potentialities assessment for the integrated and self-centered local economic development. Republic of Rwanda, Kayonza district. pp. 124. h t t p : / / w w w . k a y o n z a . g o v . $\mathrm{rw} /$ fileadmin/templates/document/Kayonza_District Potentialities.pdf (accessed 2 August 2020).

Kikulwe, E. M., Kyanjo, J. L., Kato, E., Ssali, R. T., Erima, R., Mpiira, S., \& Stoian, D. (2019). Management of Banana Xanthomonas Wilt: Evidence from impact of adoption of cultural control practices in Uganda. Sustainability, 11(9), 2610.

Kikulwe, E. M., Okurut, S., Ajambo, S., Gotor, E., Ssali, R. T., Kubiriba, J., \& Karamura, E. (2018). Does gender matter in effective management of plant disease epidemics? Insights from a survey among rural banana farming households in Uganda. Journal of Development and Agricultural Economics, 10(3), 87-98.

Kilwinger, F. B. M., Rietveld, A. M., Groot, J. C. J., \& Almekinders, C. J. M. (2019). Culturally embedded practices of managing banana diversity and planting material in Central Uganda. Journal of Crop Improvement, 33(4), 456477.

Mbaka J., Ndungo V., \& Mwangi, M. (2007). Outbreak of Xanthomonas wilt (Xanthomonas campestris pv. musacearum) on banana in Kenya. In: Recent advances in Banana crop protection for sustainable production and improved livelihoods. Programme and abstracts, ISHS/ ProMusa symposium, greenway woods resort, White River, 10-14 September 2007. Bioversity International, Montpellier, France P 58.

Minema. (2019). Socio-economic inclusion of refugees and host communities project (SEIRHCP) and environmental and social management framework (ESMF) (p. 222). Kigali, Rwanda: Ministry in charge of emergency management http://minema.gov.rw/fileadmin/user upload/Environmental_and_Social_Management_ Framework_for_SEIRHCP.pdf (

Muchuruza, Y. P., \& Melchior, H. R. (2013). The effects of Banana Xanthomonas Wilt (BXW) on food security and the people's livelihood: the case of Nshamba and Rubale divisions in Kagera Region. https://agriprofocus. com/upload/post/BXW_Research_Findings1449153812.pdf ().

Mwebaze, J. M., Tusiime, G., Tushemerweire, W. K., \& Maina, M. (2006). Development of a semi-selective medium for Xanthomonas campestris pv. musacearum. African Crop Science Journal, 14, 129-135.

Ndungo, V., Eden-Green, S., Blomme, G., Crozier, J., \& Smith, J. J. (2006). Presence of banana Xanthomonas wilt (Xanthomonas campestris pv. musacearum) in the Democratic Republic of Congo. Plant Pathology, 55, 294 294.
Nkuba, J., Tinzaara, W., Night, G., Niko, N., Jogo, W., Ndyetabula, I., \& Karamura, E. (2015). Adverse impact of Banana Xanthomonas wilt on farmers livelihoods in eastern and Central Africa. African Journal of Plant Science, 9(7), 279-286.

Ntamwira, J., Blomme, G., Bahati, L., \& Ocimati, W. (2019). Effect of timing of diseased plant cutting, altitude and banana cultivar on efficacy of singly removing Xanthomonas wilt infected banana plants. European Journal of Plant Pathology., 154, 477-489. https://doi.org/10.1007/s10658019-01671-9.

Ocimati, W., Groot, J. C. J., Tittonell, P., Taulya, G., \& Blomme, G. (2016). Effects of Xanthomonas wilt and other banana diseases on ecosystem services in banana-based agroecosystems. In X International Symposium on Banana: ISHS-ProMusa Symposium on Agroecological Approaches to Promote Innovative Banana., 1196, 19-32.

Ocimati, W., Nakato, G. V., Fiaboe, K. M., Beed, F., \& Blomme, G. (2015). Incomplete systemic movement of Xanthomonas campestris pv. musacearum and the occurrence of latent infections in Xanthomonas wilt-infected banana mats. Plant Pathology, 64(1), 81-90.

Ocimati, W., Ssekiwoko, F., Buttibwa, M., Karamura, E., Tinzaara, W., Eden-Green, S., \& Blomme, G. (2013). Systemicity and speed of movement of Xanthomonas campestris pv. musacearum in the banana plant after garden tool-mediated infection. In G. Blomme, B. Vanlauwe, \& P. van Asten (Eds.), Banana Systems in the Humid Highlands of sub-Saharan Africa: Enhancing resilience and productivity (pp. 101-108). Wallingford: CAB International.

Ocimati, W., van Schagen, B., Kozicka, M., Kikulwe, E., Gotor, E., \& Blomme, G. (2019). Banishing banana wilt: can it get any easier? Poster and handout presented at the 2nd Meeting of the Joint Boards of Bioversity International and CIAT. Maccarese, Italy, May 2019. Rome (Italy) Bioversity International. 5p. Available at: https://hdl.handle.net/10568 $/ 101557$

Okonya, J. S., Ocimati, W., Nduwayezu, A., Kantungeko, D., Niko, N., Blomme, G., Legg, J. P., \& Kroschel, J. (2019). Farmer reported Pest and disease impacts on root, tuber, and Banana crops and livelihoods in Rwanda and Burundi. Sustainability, 11, 1592. https://doi.org/10.3390 /su11061592.

Peel, M. C., Finlayson, B. L., \& McMahon, T. A. (2007). Updated world map of the Köppen-Geiger climate classification. Hydrology and Earth System Sciences, 11, 1633-1644.

Pircher, T., Almekinders, C. J. M., \& Kamangwa, C. G. (2013). Participatory trials and farmers' social realities: Understanding the adoption of legume technologies in a Malawian farmer community. International Journal of Agricultural Sustainability, 11(3), 252-263.

R core team (2018). R: A language and environment for statistical computing. URL https://www.R-project.org/.

Reeder, R. H., Muhinyuza, J. B., Opolot, O., Aritua, V., Crozier, J., \& Smith, J. (2007). Presence of banana bacterial wilt (Xanthomonas campestris pv. musacearum) in Rwanda. New disease reports. Plant Pathology, 56, 1038.

Rietveld, A., \& Farnworth, C. R. (2018a). Continuity and change: Negotiating gender norms in agricultural research for development in Rwanda. GENNOVATE resources for scientists and research teams. CDMX, Mexico: CIMMYT. 
Rietveld, A., \& Farnworth, C. R. (2018b). Towards genderresponsive banana research for development in the eastAfrican highlands. GENNOVATE resources for scientists and research teams. CDMX, Mexico: CIMMYT.

Rietveld, A. M., Jogo, W., Mpiira, S., \& Staver, C. (2014). The effect of Banana Xanthomonas wilt on beer-banana value chains in Central Uganda. Journal of Agribusiness in Developing and Emerging Economies, 4(2), 172-184.

Rutikanga, A., Sivirihauma, C., Ocimati, W., Night, G., Murekezi, C., Ndungo, V., Mugiraneza, T., Rurangwa, E., \& Blomme, G. (2016). Breaking the cycle of Xanthomonas campestris pv. musacearum in infected fields through the cultivation of annual crops and disease control in adjacent fields. Journal of Phytopathology, 164(9), 659-670.

Sinja, J., Karugia, J., Baltenweck, I., Waithaka, M., Miano, M. D., Nyikal, R. \& Romney, D. (2004). Farmer Perception of Technology and its Impact on Technology Uptake: The Case of Fodder Legume in Central Kenya Highlands. African Association of Agricultural Economists. Shaping the Future of African Agriculture for Development: The Role of Social Scientists. In: Proceedings of the Inaugural Symposium, 6 to 8 December 2004, Grand Regency Hotel, Nairobi, Kenya. https://www.researchgate. net/publication/23504089_Farmer_Perception_of_ Technology_and_its_Impact_on_Technology_Uptake_The Case_of_Fodder_Legume_in_Central_Kenya_Highlands. Accessed 25 June 2020.

Sivirihauma, C., Rutikanga, A., Murekezi, C., Blomme, G., Anuarite, U., Ocimati, W., Lepoint, P., \& Ndungo, V. (2013). Effect of length of fallow period after total uprooting of a Xanthomonas Wilt-infected banana field on infection of newly established planting materials: Case studies from Rwanda and Eastern Democratic Republic of Congo. In: Blomme, G., van Asten, P. \& Vanlauwe, B. (eds.): Banana systems in the humid highlands of sub-Saharan Africa: Enhancing resilience and productivity. CABI, Wallingford, Oxfordshire, UK, pp. 125-130.

Ssekiwoko, F., Taligola, H. K., \& Tushmereirwe, W. K. (2006). Xanthomonas campestris pv. musacearum host range in Uganda. African Crop Science Journal, 14, 111-120.

Tinzaara, W., Gold, C. S., Ssekiwoko, F., Tushemereirwe, W., Bandyopadhyay, R., Abera, A., \& Eden-Green, S. J. (2006).
Role of insects in the transmission of banana bacterial wilt. African Crop Science Journal, 14, 105-110.

Turyagyenda, L. F., Blomme, G., Ssekiwoko, F., \& Eden-Green, S. (2007). Determination of the appropriate fallow period to control Xanthomonas wilt following infection of banana. ISHS/ProMusa symposium. Recent advances in banana crop protection for sustainable production and improved livelihoods. Greenway woods resort, White River, South Africa, September 10-14, 2007. Programme and abstracts booklet. Pp. 58-59.

Tushemereirwe, W. K., Kangire, A., Ssekiwoko, F., Offord, L. C., Crozier, J., Boa, E., Rutherford, M., \& Smith, J. J. (2004). First report of Xanthomonas campestris pv. musacearum on Banana in Uganda. Plant Pathology, 53, 802.

Tushemereirwe, W. K., Okaasai, O., Kubiriba, J., Nankinga, C., Muhangi, J., Odoi, N., \& Opio, F. (2006). Status of banana bacterial wilt in Uganda. African Crop Science Journal, 14, 73-82.

UPCE Consult (2012). Final report of implementation of Kayonza town master plan. Ministry of infrastructure, Rwanda housing authority, Kayonza district, Eastern Province, Republic of Rwanda.pp. 384. http://www.kayonza.gov. $\mathrm{rw} /$ fileadmin/templates/document/Implementation_of Kayonza_Master_Plan.pdf. (accessed 28 August 2020).

Verdoodt, A., \& Van Ranst, E. (2003). A large-scale land suitability classification for Rwanda. In: Land evaluation for agricultural production in the tropics. Laboratory of Soil Science. Ghent University, Belgium. pp. 183.

Wickham, H., Averick, M., Bryan, J., Chang, W., D’Agostino McGowan, L., François, R., et al. (2019). Welcome to the tidyverse. Journal of Open Source Software, 4(43), 1686. https://doi.org/10.21105/joss.01686.

Wickham H., François R., Henry L. and Müller K. (2020). Dplyr: A grammar of data manipulation. $\mathrm{R}$ package version 1.0.0. https://CRAN.R-project.org/package=dplyr

Yirgou, D., \& Bradbury, J. F. (1968). Bacterial wilt of enset (Ensete ventricosum) incited by Xanthomonas musacearum sp.n. Phytopathology, 58, 111-112.

Yirgou, D., \& Bradbury, J. F. (1974). A note on wilt of banana caused by the enset wilt organism Xanthomonas musacearum. East African Agricultural and Forestry Journal, 40, 111-114. 